\title{
AN ACTIVE INTERMEDIATE FORMED IN THE REACTION OF BLEOMYCIN-Fe(II) COMPLEX WITH OXYGEN
}

\author{
Hiroshi Kuramochi, Katsutoshi Takahashi, Tomohisa Takita* \\ and Hamao Umezawa* \\ Research Laboratories, Pharmaceutical Division, Nippon Kayaku Co., \\ Shimo, Kita-ku, Tokyo 115, Japan \\ *Institute of Microbial Chemistry \\ Kamiosaki, Shinagawa-ku, Tokyo 141, Japan
}

(Received for publication January 27, 1981)

\begin{abstract}
The base-release activity of oxygen adduct of bleomycin-Fe(II) complex [BLM-Fe(II)] from DNA decreased with a half-life of 5.2 minutes, when incubated at $0^{\circ} \mathrm{C}$ in $0.05 \mathrm{M}$ Tris- $\mathrm{HCl}$ buffer at pH 7.8 in the absence of DNA. Under the same condition, however, visible and ESR spectra showed that the adduct was immediately converted into the ferric complex. The ESR study further indicated the simultaneous formation of two kinds of the low-spin BLM-Fe(III) complex. One of them disappeared in parallel with the decrease of the base-release activity and transformed into the other. The latter Fe(III) complex was stable but inactive. However, by addition of hydrogen peroxide to the latter, the former was regenerated and the base-release activity appeared. Oxygen concentration measurements by oxygraph showed that one mole of BLM-Fe(II) consumed approximately 0.5 mole of molecular oxygen instantly, but did not any more thereafter in the absence of a reducing agent. While in the presence of 2-mercaptoethanol, the oxygen consumption proceeded biphasically, and equimolar oxygen was consumed by $\mathrm{BLM}-\mathrm{Fe}(\mathrm{II})$ in the first rapid reaction. These results suggest that oxygen adduct of BLM-Fe (II) is reduced by one electron transfer from an external electron donor and the resulting BLM$\mathrm{Fe}(\mathrm{III})-\mathrm{O}_{2} \mathrm{H}^{-}$[or its deprotonated form: $\mathrm{BLM}-\mathrm{Fe}(\mathrm{III})-\mathrm{O}_{2}{ }^{2-}$ ] shows the activity to break DNA accompanying the base-release.
\end{abstract}

Bleomycin (BLM) is a group of glycopeptide antitumor antibiotics discovered by UMEZAwA et al. from the culture filtrate of Streptomyces verticillus ${ }^{1)}$. The cytotoxicity of BLM has been found to be related to its ability to induce intracellular breakage of $\mathrm{DNA}^{2,3)}$. DNA degradation by BLM in vitro occurs in the presence of ferrous ion and molecular oxygen, and it is promoted by addition of hydrogen peroxide and reducing agents such as 2-mercaptoethanol, dithiothreitol and ascorbic acid ${ }^{4 \sim 8)}$. BLM with ferric ion does not cause DNA degradation in the absence of a reducing agent, but does it in the presence of the reducing agent $t^{0,10}$. BLM forms a complex with ferrous ion ${ }^{11)}$ and the three-dimensional structures of BLM-Fe(II) complex and its oxygen adduct were proposed on the basis of X-ray crystallographic analysis of the $\mathrm{Cu}(\mathrm{II})$ complex of a biosynthetic intermediate of $\mathrm{BLM}^{12,13)}$. Formation of BLM-Fe(II)- $\mathrm{O}_{2}$ complex and its conversion into BLM-Fe(III) complex accompanied with generation of reactive oxygen radical species, $\mathrm{O}_{2}-$ and $\cdot \mathrm{OH}$, were reported ${ }^{14,15)}$. However, several investigators have obtained the different results on the effect of radical scavengers on DNA degradation by BLM ${ }^{4,8,11,16)}$, therefore, the active species, which attacks DNA, remains unconfirmed. We have characterized the active intermediate to cause DNA strand scission formed during the oxidation of BLM-Fe(II) to BLM$\mathrm{Fe}(\mathrm{III})$ by oxygen. 


\section{Materials and Methods}

\section{Chemicals}

Bleomycin A2 (BLM) was prepared at the research laboratory of Nippon Kayaku Co., Tokyo, and molar concentrations of the drug were determined on the basis of the molecular weight of 1,487. Calf thymus DNA was purchased from Sigma Chemical Co., Saint Louis, Catalase from Miles Laboratories, Ltd., Elkhart, IN, $\mathrm{Fe}\left(\mathrm{NH}_{4}\right)_{2}\left(\mathrm{SO}_{4}\right)_{2} \cdot 6 \mathrm{H}_{2} \mathrm{O}$ from Hikotaro Shuzui Co., Tokyo, hydrogen peroxide from Mitsubishi Gas Chemical Co., Tokyo, and 2-mercaptoethanol (2-ME) from Tokyo Kasei Kogyo Co., Tokyo.

Determination of the Base-release Activity of BLM

The base-release reactions were conducted for 5 minutes at $37^{\circ} \mathrm{C}$. The reaction mixtures consisted of $0.05 \mathrm{M}$ Tris- $\mathrm{HCl}$, pH 7.8, various concentrations of BLM-Fe(II), $1 \mathrm{mg} / \mathrm{ml}$ calf thymus DNA. The amount of thymine released from DNA was measured by high performance liquid chromatography in the same way as described previously, except using Brownlee MPLC Guard Column Anion (Brownlee Labs. Inc., Santa Clara) in the place of DEAE-Sephadex A-25 $5^{\text {) }}$.

\section{Optical and ESR Spectra}

Optical absorption spectra were recorded with a Hitachi model 200-20 spectrophotometer equipped with a thermoregulated assembly. X-Band ESR spectra were obtained at 77K with a JEOL JES-PE-1X spectrometer with $100 \mathrm{kHz}$ field modulation. Samples in quartz tubes were frozen with liquid nitrogen. The $g$-values were calibrated with 1,1-diphenyl-2-picrylhydrazyl $(g=2.0036)$ and $\mathrm{Mn}(\mathrm{II})$ in $\mathrm{MgO}$ $\left(\Delta \mathrm{H}_{3-4}=86.9 \mathrm{G}\right)$.

\section{Oxygen Consumption}

Oxygen consumption was measured by a Gilson Model K-ICT-O oxygraph with a Clark electrode and calibrated by the method described by ROBINSON and COOPER ${ }^{17)}$.

\section{Results}

The degree of DNA degradation by BLM, Fe(II) and oxygen can be shown by the amount of the released thymine, which is quantitatively measured by high performance liquid chromatography ${ }^{9)}$. The

Fig. 1. Inactivation rate of the thymine-release activity of $\mathrm{BLM}$ with $\mathrm{Fe}(\mathrm{II})$ and oxygen at $0^{\circ} \mathrm{C}$ at $\mathrm{pH} 7.8$.

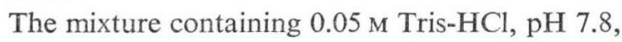
$0.24 \mathrm{~mm}$ BLM and $0.20 \mathrm{~mm}$ Fe(II) was incubated at $0^{\circ} \mathrm{C}$ under aerobic condition. Ferrous ion was added last. At the indicated incubation time, aliquot of the mixture was added to DNA solution to measure the remaining base-release activity by the method described in Materials and Methods.

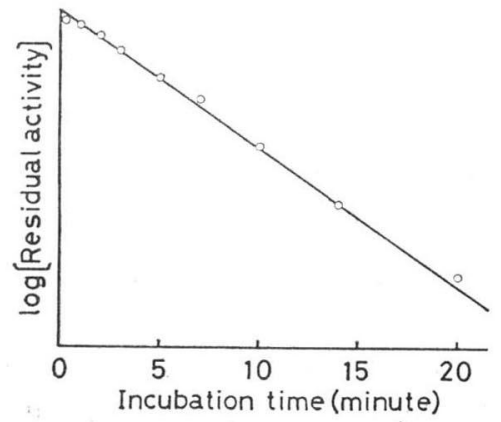

amount of the released thymine correlates linearly with the concentration of BLM-Fe (II). Therefore, the kinetics of DNA degradation by BLM can be studied by this system. We found that the thymine-release activity of BLM was completely lost within one minute of incubation at $37^{\circ} \mathrm{C}$ at $\mathrm{pH} 7.8$ after complex formation between BLM and Fe(II) under aerobic condition, while at $0^{\circ} \mathrm{C}$ the activity decreased gradually as shown in Fig. 1, which shows that the inactivation process obeys first-order kinetics with a half-life of 5.2 minutes.

When BLM was mixed with ferrous ion at $0^{\circ} \mathrm{C}$ under aerobic condition, the visible absorption spectrum showed instant formation of BLMFe(III) complex (Fig. 2), which was similar to that formed from BLM and ferric ion described by SAUSVIlle et al. ${ }^{18)}$, although the latter did not 
Fig. 2. Visible absorption spectrum immediately after addition of ferrous ion to BLM solution at $0^{\circ} \mathrm{C}, \mathrm{pH} 7.8$ under aerobic condition.

Experimental conditions were the same as described in Fig. 1.

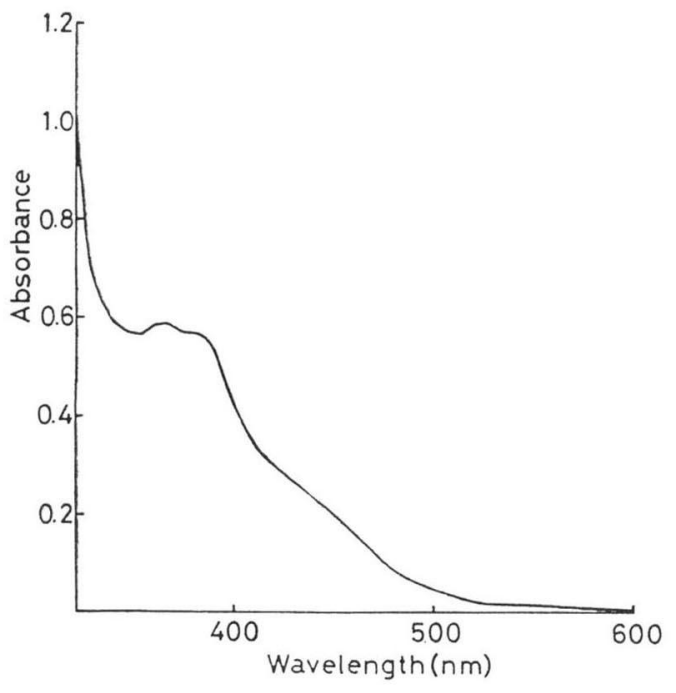

show the DNA-degradation activity.

Fig. 3 shows the time-course of the ESR spectral change after mixing BLM with ferrous ions at $0^{\circ} \mathrm{C}$ at $\mathrm{pH} 7.8$ under aerobic condition.
Fig. 3. ESR spectral changes after addition of ferrous ion to $\mathrm{BLM}$ solution at $0^{\circ} \mathrm{C}, \mathrm{pH} 7.8$ under aerobic condition.

Experimental conditions were the same as described in Fig. 1. The spectra were recorded at the following times: (A) 30 seconds, (B) 5 minutes, (C) 10 minutes and (D) 5 minutes after addition of $10 \mathrm{~mm}$ hydrogen peroxide to BLM-Fe(III) complex.

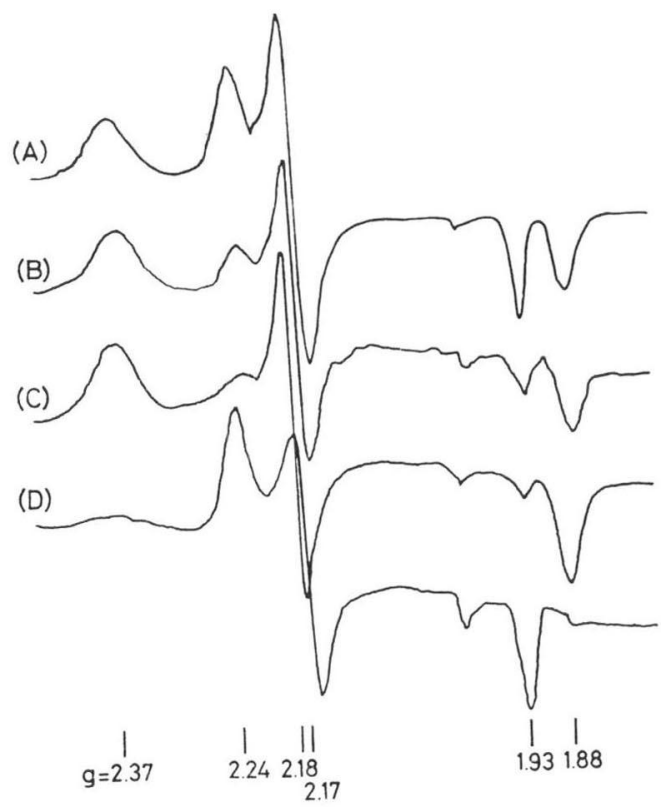

Two low-spin ferric species were detected within 30 seconds. One has the g-values of $2.24,2.17$ and 1.93, and the other has $2.37,2.18$ and 1.88. The former species, which exhibited the reduced spread in g-value, disappeared with a half-life of about 5 minutes and was converted into the latter. The disappearance of the former species was in parallel with the loss of the base-release activity. This result suggested the BLM-Fe(III) complex with the reduced spread in g-value to be an active intermediate.

Fig. 4 shows oxygen uptake by BLM-Fe(II) complex at $0^{\circ} \mathrm{C}$ or $37^{\circ} \mathrm{C}$ at $\mathrm{pH} 7.8$ in the absence or presence of 2-ME. The oxygen uptake completed within one minute in the absence of 2-ME at both temperature. This result corresponded to the rapid appearance of BLM-Fe(III) complex detected by visible and ESR spectra. The molar ratios of oxygen consumed by BLM-Fe(II) complex were 0.48 at $0^{\circ} \mathrm{C}$ and 0.44 at $37^{\circ} \mathrm{C}$, and in the presence of DNA it was 0.59 at $37^{\circ} \mathrm{C}$. In the presence of 2-ME, "the oxygen uptake proceeded biphasically, and the molar ratio of the consumed oxygen to BLM-Fe(II) in the initial phase was 0.86 at $37^{\circ} \mathrm{C}$, about two times of that in the absence of 2-ME (Table 1). Since BLM-Fe (II) complex consumed about 0.5 equivalent oxygen in the absence of the reducing agent, there was a possibility that the oxygen was reduced by two electron transfer to form hydrogen peroxide. Therefore, the oxygen uptake was examined in the presence of catalase. As shown in Table 1, catalase had no influence upon the oxygen uptake by BLM-Fe(II) complex, that is, no hydrogen peroxide was generated in this redox system in the absence or presence of DNA.

It is reported that DNA strand scission by BLM is stimulated not only by various reducing agents, but also by hydrogen peroxide ${ }^{6,8}$. Our experiment shown in Fig. 5 also indicated that the thymine- 
Fig. 4. Oxygen uptake by BLM-Fe(II) at $\mathrm{pH} 7.8$.

$\mathrm{BLM}$, ferrous ion and 2-ME were added in the order indicated in the figure. Temperature: (A) and (B) $37^{\circ} \mathrm{C}$; (C) $0^{\circ} \mathrm{C}$

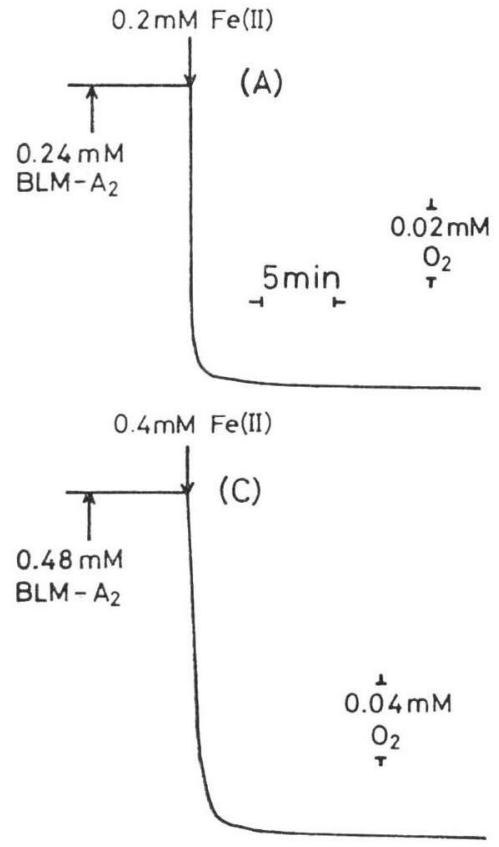

Table 1. Molar ratio of oxygen consumed by BLM A2-Fe(II) complex.

\begin{tabular}{c|c}
\hline \multicolumn{1}{c|}{ Conditions } & Consumed $\mathrm{O}_{2}$ \\
\cline { 2 - 2 } & BLM A2-Fe(II) \\
\hline $0.2 \mathrm{~mm} \mathrm{BLM} \mathrm{A2-Fe}(\mathrm{II})$ & $0.44(\mathrm{M} / \mathrm{M})$ \\
$+10 \mathrm{~mm} 2-\mathrm{ME}$ & $0.86^{*}$ \\
$+74 \mu \mathrm{g} / \mathrm{ml} \mathrm{catalase}$ & 0.45 \\
$+1 \mathrm{mg} / \mathrm{ml} \mathrm{DNA}$ & 0.59 \\
$+1 \mathrm{mg} / \mathrm{ml} \mathrm{DNA}, 74 \mu \mathrm{g} / \mathrm{ml}$ catalase & 0.59 \\
$0.2 \mathrm{~mm} \mathrm{BLM} \mathrm{A2-Fe}(\mathrm{II})\left(0^{\circ} \mathrm{C}\right)$ & 0.48 \\
\hline
\end{tabular}

* $\mathrm{O}_{2}$ consumption at the first phase.

Reaction mixtures contained $0.05 \mathrm{M}$ Tris- $\mathrm{HCl}$, pH 7.8, 0.24 mM BLM, $0.20 \mathrm{~mm}$ ferrous ion, and substance as indicated. Reactions were initiated by addition of ferrous ion and carried at $37^{\circ} \mathrm{C}$, except the last line $\left(0^{\circ} \mathrm{C}\right)$.

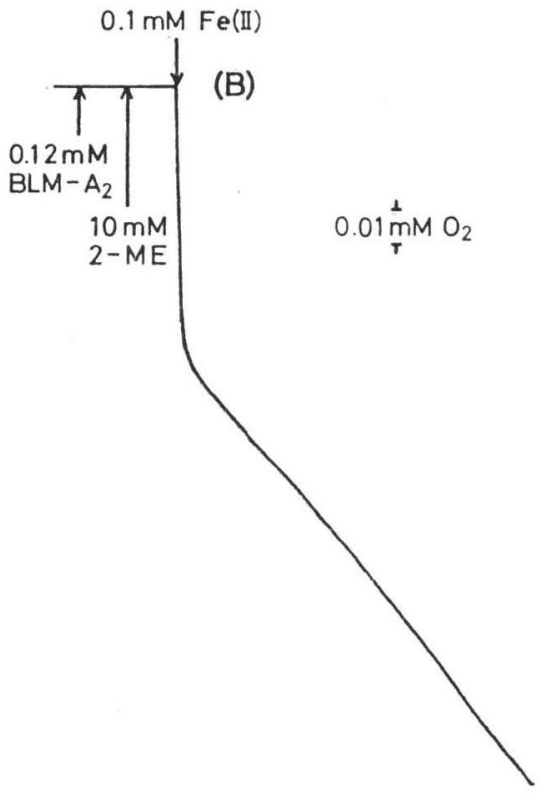

Fig. 5. Thymine-release from DNA by BLM-Fe (III) complex in the presence of hydrogen peroxide. The reaction mixture contained $0.05 \mathrm{M}$ Tris $-\mathrm{HCl}$, $\mathrm{pH} 7.8,0.05 \mathrm{~mm}$ BLM-Fe(III) complex, $1 \mathrm{mg} / \mathrm{ml}$ calf thymus DNA, and 0, 1 and $10 \mathrm{~mm}$ hydrogen peroxide. BLM-Fe(III) complex was prepared by oxidation of BLM-Fe(II) complex. The reactions were carried out at $37^{\circ} \mathrm{C}$.

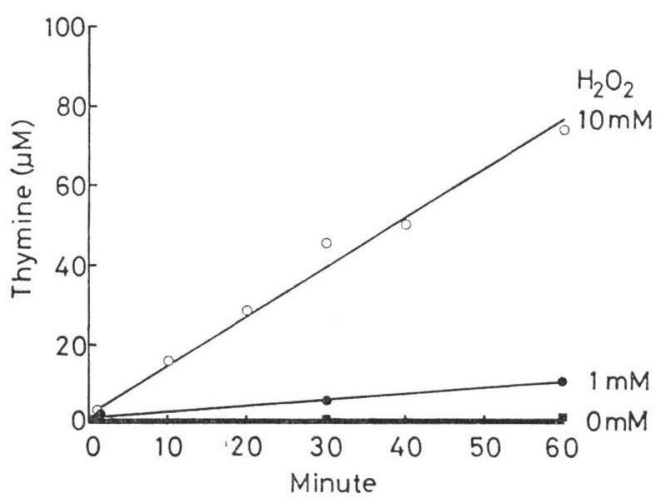

release activity appeared by addition of hydrogen peroxide to the inactive BLM-Fe(III) complex. To investigate the active intermediate formed from the inactive BLM-Fe(III) complex and hydrogen peroxide, the ESR spectrum was measured (the bottom spectrum in Fig. 3). The formation of the active low-spin BLM-Fe(III) complex with the reduced spread in g-value, which was identical with the active intermediate formed immediately after mixing BLM with ferrous ion at $0^{\circ} \mathrm{C}$ under aerobic condition, was 
confirmed, although it took a few minutes to finish the complete conversion.

\section{Discussion}

It has been reported that molecular oxygen and ferrous ion are essential for DNA strand scission by $\mathrm{BLM}^{4 \sim 8)}$. Most investigators have the view that oxygen is reduced by BLM-Fe(II) complex and the resulting oxygen radicals such as $\mathrm{O}_{2}-$ and $\cdot \mathrm{OH}$ attack DNA and cause the strand scission concomitant with release of the DNA bases ${ }^{10,11,14 \sim 16,19,20)}$.

As shown by the visible and ESR spectra (Figs. 2 and 3), BLM-Fe(II) complex is immediately oxidized to $\mathrm{BLM}-\mathrm{Fe}(\mathrm{III})$ complex even at $0^{\circ} \mathrm{C}$ under aerobic condition. However, under the same condition the thymine-release activity of BLM decreased gradually with a half-life of 5.2 minutes (Fig. 1). This fact suggests that the active intermediate of BLM-iron complex is a kind of BLM-Fe(III) complex. The ESR study further indicated that two kinds of low-spin BLM-Fe(III) complex (one has the g-values of 2.24, 2.17 and 1.93 and the other has $2.37,2.18$ and 1.88) were formed simultaneously and almost equally (Fig. 3). We found that the former complex with the reduced spread in g-value disappeared almost in parallel with the decrease of the thymine-release activity of BLM, and was transformed to the latter. Therefore, the former Fe(III) complex was considered to be the active form of BLM-iron complex. BLM-Fe(III) complex formed directly from BLM and ferric ion gave the same ESR spectrum as the latter and had no activity ${ }^{21)}$. Therefore, the active BLM-Fe(III) complex should carry a reactive oxygen at its sixth coordination site.

We found that one mole of BLM-Fe(II) complex consumed approximately 0.5 mole of molecular oxygen in the absence of $2-\mathrm{ME}$, and during this oxygen-consumption process no hydrogen peroxide was liberated (Table 1). While in the presence of 2-ME, the equimolar oxygen was consumed in the first phase reaction. We also found that addition of hydrogen peroxide to the inactive BLM-Fe(III) complex regenerated the active BLM-Fe(III) complex with the reduced spread in g-value (Fig. 3), and the baserelease activity appeared (Fig. 5). These results suggest that the oxygen adduct of BLM-Fe(II) complex, (which is represented here as BLM-Fe(II)- $\mathrm{O}_{2}$ but there may be some contribution from BLM-Fe(III)$\mathrm{O}_{2}^{-}$), is reduced by one electron transfer from an external electron donor to form the active form, BLM$\mathrm{Fe}(\mathrm{III})-\mathrm{O}_{2} \mathrm{H}^{-}$, or its deprotonated form, BLM-Fe(III)- $\mathrm{O}_{2}{ }^{2-}$. The formation pathways of the active form are formulated as follows.

1) $\mathrm{BLM}-\mathrm{Fe}(\mathrm{II})-\mathrm{O}_{2}+\mathrm{BLM}-\mathrm{Fe}(\mathrm{II}) \longrightarrow \mathrm{BLM}-\mathrm{Fe}(\mathrm{III})-\mathrm{O}_{2} \mathrm{H}^{-}+$inactive BLM-Fe(III)

2) $\mathrm{BLM}-\mathrm{Fe}(\mathrm{II})-\mathrm{O}_{2}+$ Reductant $\longrightarrow \mathrm{BLM}-\mathrm{Fe}(\mathrm{III})-\mathrm{O}_{2} \mathrm{H}^{-}$

3) inactive $\mathrm{BLM}-\mathrm{Fe}(\mathrm{III})+\mathrm{H}_{2} \mathrm{O}_{2} \longrightarrow \mathrm{BLM}-\mathrm{Fe}(\mathrm{III})-\mathrm{O}_{2} \mathrm{H}^{-}$

In the absence of the reducing agent, the electron to reduce $\mathrm{BLM}-\mathrm{Fe}(\mathrm{II})-\mathrm{O}_{2}$ is ultimately supplied from the ferrous iron of other BLM-Fe(II), although the mechanism of the electron transfer (such as via the $\mu$-peroxo complex, BLM-Fe(II)- $\left.\mathrm{O}_{2}-\mathrm{Fe}(\mathrm{II})-\mathrm{BLM}\right)$ must be clarified in further study [reaction 1)]. This reaction is supported by the ESR study which showed that two kinds of low-spin BLM-Fe(III) complex were formed simultaneously and almost equally. Sugiura et al. ${ }^{14)}$ also has observed these two kinds of low-spin ferric species. However, the stable low-spin ferric species was not detected at the very early stage (3 seconds at $\mathrm{pH} 6.9$ ) in the reaction of BLM-Fe(II) with oxygen. SugIurA tentatively assigned these two kinds of low-spin ferric species to $\mathrm{BLM}-\mathrm{Fe}(\mathrm{III})-\mathrm{H}_{2} \mathrm{O}$ (unstable) and $\mathrm{BLM}-\mathrm{Fe}(\mathrm{III})-\mathrm{OH}^{-}$ (stable). ${ }^{21} \quad$ The stable low-spin ferric species observed in the initial stage by us is suggested to be produced via a high-spin ferric species. The presence of the high-spin ferric species at the initial step has been shown by DABROWIAK ${ }^{22)}$. It is reasonable to speculate that the high-spin ferric species, of which the sixth coordination site should be vacant, is transformed to the stable low-spin ferric species by ligation of $-\mathrm{OH}$ at the vacant sixth coordination site. Our observation of two kinds of the low-spin ferric species and no detection of the high-spin

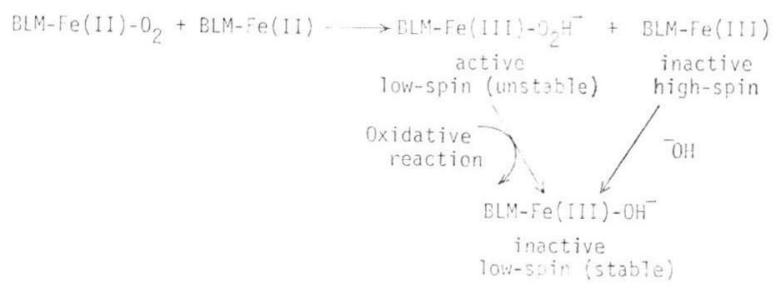


ferric species at the initial stage can be reasonably explained by the rapid and complete transformation of the high-spinspecies to the stable low-spin species. In our experimental condition at $\mathrm{pH} 7.8$ (which is higher than 6.9) and 30 seconds, this transformation should occur rapidly and be completed. The reaction process 1) may be shown more in detail as p. 580 .

Exposure of oxyhaemoglobin $\left[\mathrm{Hb}-\mathrm{Fe}(\mathrm{II})-\mathrm{O}_{2}\right]$ to ${ }^{60} \mathrm{Co} \gamma$-rays at $77 \mathrm{~K}$ gave $\mathrm{Hb}-\mathrm{Fe}(\mathrm{III})-\mathrm{O}_{2}{ }^{2-}$ and its protonated form by electron capture ${ }^{23)}$, whose g-values are very close to those of the active form of BLM-Fe(III) complex. This is an support to our proposed $\mathrm{BLM}-\mathrm{Fe}(\mathrm{III})-\mathrm{O}_{2} \mathrm{H}^{-}$structure for the active form. This structure is also supported by the direct formation of the active form from the inactive BLM-Fe(III) complex and hydrogen peroxide [reaction 3)]. In the presence of a reducing agent, BLM$\mathrm{Fe}(\mathrm{II})-\mathrm{O}_{2}$ seems to be reduced by the reducing agent [reaction 2)]. The slow oxygen uptake in the second phase in the presence of 2-ME appears to be due to oxygen uptake of recycled BLM-Fe(II) ${ }^{9)}$ (see Fig. 6) and oxygenation of the reducing agent.

Fig. 6 shows our proposed reaction pathway of BLM action to DNA. The reducing agent such as 2-ME plays its role in the two ways: first, the reductive production of the active intermediate, BLM$\mathrm{Fe}(\mathrm{III})-\mathrm{O}_{2} \mathrm{H}^{-}$, from BLM-Fe(II)- $\mathrm{O}_{2}$ complex, second, the reductive regeneration of BLM-Fe(II) complex from the inactive BLM-Fe(III) complex ${ }^{9)}$. The active intermediate is also produced directly from the inactive BLM-Fe(III) and hydrogen peroxide. Accordingly, molecular oxygen and reducing agents are not necessarily required for DNA degradation by BLM-iron complex in the presence of hydrogen peroxide. However, since the concentration of reducing agent such as ascorbic acid and sulfhydryl compounds is much higher than that of hydrogen peroxide in cells ${ }^{24)}$, the pathway including molecular oxygen and the reducing agents should be more important for the action of BLM to DNA in vivo.

We have observed that no hydrogen peroxide is liberated in the redox reaction between BLM-Fe(II) and molecular oxygen and in the DNA-degradation reaction. Several investigators have claimed that superoxide or hydroxyl radical are responsible for the DNA degradation by $\mathrm{BLM}^{15,16,20)}$. Future work is directed at pursuing the reactive oxygen species of $\mathrm{BLM}-\mathrm{Fe}(\mathrm{III})-\mathrm{O}_{2} \mathrm{H}^{-}\left(\right.$or $-\mathrm{O}_{2}{ }^{2-}$ ) in the DNA-degradation reaction.

Fig. 6. Proposed reaction pathway leading to DNA degradation by BLM-iron complex.

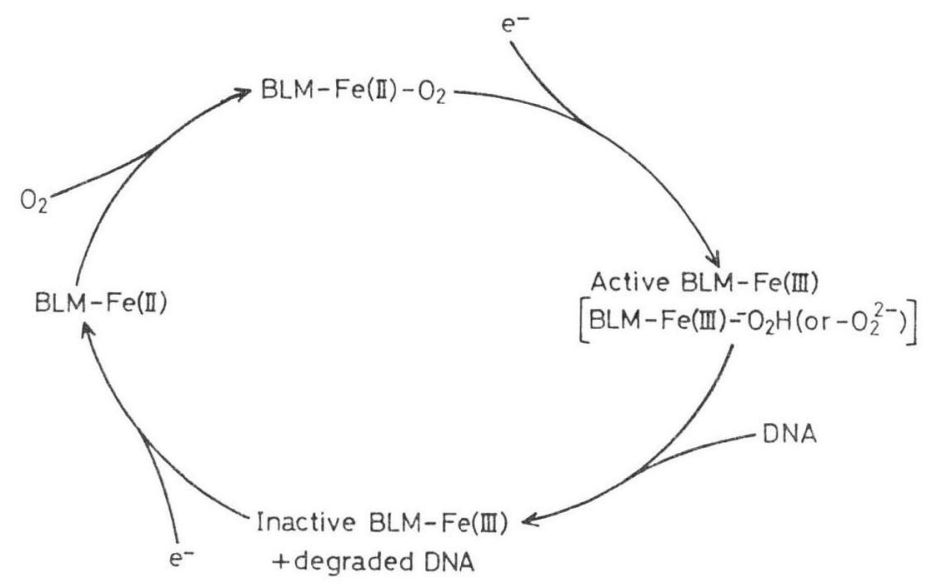

Acknowledgments

We acknowledge Mr. TAKA'AKI OHKUMA and Dr. YUtAKA KIRINo for performing ESR measurement. We also wish to thank Drs. Kazuhiko Ishizu, Akira Nishinaga and Yukio Sugiura for helpful discussions.

References

1) Umezawa, H.; K. Maeda, T. Takeuchi \& Y. Okami: New antibiotics, bleomycin A and B. J. Antibiotics, Ser. A 19: 200 209, 1966 
2) Suzuki, H.; K. Nagai, H. Yamaki, N. Tanabe \& H. Umezawa: On the mechanism of action of bleomycin: Scission of DNA strands in vitro and in vivo. J. Antibiotics 22: 446 448, 1969

3) Terashima, T.; M. Yasukawa \& H. Umezawa: Breaks and rejoining of DNA in cultured mammalian cells treated with bleomycin. GANN 61: 513 516, 1970

4) IsHIDA, R. \& T. TAKAHASHI: Increased DNA chain breakage by combined action of bleomycin and superoxide radical. Biochem. Biophys. Res. Comm. 66: 1432 1438, 1975

5) Sausville, E. A.; J. Peisach \& S. B. Horwitz: A role for ferrous ion and oxygen in the degradation of DNA by bleomycin. Biochem. Biophys. Res. Comm. 73: 814 822, 1976

6) ONISHI, T.; H. Iwata \& Y. TAKAGI: Effects of reducing agents on action of bleomycin. J. Biochem. 77 : $745 \sim 752,1975$

7) Nagai, K.; H. Suzuki, N. Tanaka \& H. Umezawa: Decrease of melting temperature and single strand scission of DNA by bleomycin in the presence of 2-mercaptoethanol. J. Antibiotics 22: 569 573, 1969

8) Nagai, K.; H. Suzuki, N. Tanaka \& H. Umezawa: Decrease of melting temperature and single strand scission of DNA by bleomycin in the presence of hydrogen peroxide. J. Antibiotics 22: 624 628, 1969

9) Ekimoto, H.; H. Kuramochi, K. Takahashi, A. Matsuda \& H. Umezawa: Kinetics of the reaction of bleomycin-Fe(II)- $\mathrm{O}_{2}$ complex with DNA. J. Antibiotics 33: 426 434, 1980

10) Povirk, L. F.: Catalytic release of deoxyribonucleic acid bases by oxidation and reduction of an iron . bleomycin complex. Biochemistry 18: 3989 3995, 1979

11) Sausville, E. A.; R. W. Stein, J. A. Peisach \& S. B. Horwitz: Properties and products of the degradation of DNA by bleomycin and iron (II). Biochemistry 17:2746 2754, 1978

12) Ittaka, Y.; H. Nakamura, T. Nakatani, Y. Muraoka, A. Fuji, T. Takita \& H. Umezawa: Chemistry of bleomycin. XX. The X-ray structure determination of P-3A Cu(II)-complex, a biosynthetic intermediate of bleomycin. J. Antibiotics 31: 1070 1072, 1978

13) Takita, T.; Y. Muraoka, T. Nakatani, A. Fujit, Y. Iitaka \& H. Umezawa: Chemistry of bleomycin. XXI. Metal-complex of bleomycin and its implication for the mechanism of bleomycin action. J. Antibiotics 31: 1073 1077, 1978

14) SugIURA, Y. \& T. KIKUCHI: Formation of superoxide and hydroxy radicals in iron(II)-bleomycin-oxygen system: Electron spin resonance detection by spin trapping. J. Antibiotics 31: 1310 1312, 1978

15) Oberley, L. W. \& G. R. Buettner: The production of hydroxyl radical by bleomycin and iron(II). FEBS Lett. 97: 47 49, 1979

16) Lown, J. W. \& S. Sim: The mechanism of the bleomycin-induced cleavage of DNA. Biochem. Biophys. Res. Comm. 77: 1150 1157, 1977

17) Robinson, J. \& J. M. COOPER: Method of determing oxygen concentrations in biological media, suitable for calibration of the oxygen electrode. Anal. Chem. 33: 390 399, 1970

18) Burger, R. M.; J. Peisach, W. E. Blumberg \& S. B. Horwitz: Iron-bleomycin interactions with oxygen and oxygen analogues. J. Biol. Chem. 254: 10906 10912, 1979

19) Sausville, E. A.; J. Peisach \& S. B. Horwitz: Effect of chelating agents and metal ions on the degradation of DNA by bleomycin. Biochemistry 17: 2740 2746, 1978

20) Takeshita, M. \& A. P. Grollman: A molecular basis for the interaction of bleomycin with DNA. Bleomycin: Chemical, Biochemical, and Biological Aspects (HeCHT, S., Ed.), pp. 207 221, SpringerVerlag, New York, 1979

21) Sugrura, Y.: Bleomycin-iron complexes. Electron spin resonance study, ligand effect, and implication for action mechanism. J. Am. Chem. Soc. 102: 5208 5215, 1980

22) Dabrowiak, J. C.: The metallobleomycins. Bleomycin: Chemical, Biochemical and Biological Aspects (Hecht, S., Ed.), pp. 137 155, Springer-Verlag, New York, 1979

23) Symons, M. C. R. \& R. L. Peterson: Electron capture by oxyhaemoglobin: An e.s.r. study. Proc. R. Soc. Lond. B. $201: 285 \sim 300,1978$

24) Oshino, N.; B. Chance, H. Sies \& T. Bucher: The role of $\mathrm{H}_{2} \mathrm{O}_{2}$ generation in perfused rat liver and the reaction of catalase compound I and hydrogen donors. Arch. Biochem. Biophys. 154: 117 131, 1973 